\title{
The significance of post-translational removal of a-DG-N in early stage endometrial cancer development
}

\author{
Sophea Heng 1,2,3, Jemma Evans $^{1,2,4}$, Lois A. Salamonsen ${ }^{1,2,4}$, Tom W. Jobling ${ }^{4,5}$ and \\ Guiying $\mathrm{Nie}^{1,2,3}$ \\ ${ }^{1}$ Centre for Reproductive Health, Hudson Institute of Medical Research, Clayton, Victoria, Australia \\ ${ }^{2}$ Department of Molecular and Translational Sciences, Monash University, Clayton, Victoria, Australia \\ ${ }^{3}$ Department of Biochemistry and Molecular Biology, Monash University, Clayton, Victoria, Australia \\ ${ }^{4}$ Department of Obstetrics and Gynaecology, Monash University, Clayton, Victoria, Australia \\ ${ }^{5}$ Epworth Research Institute, Epworth Health Care, Richmond, Victoria, Australia
}

Correspondence to: Guiying Nie, email: guiying.nie@hudson.org.au

Keywords: endometrial cancer, dystroglycan, tight junction, cell polarity, estrogen

Received: October 25, $2016 \quad$ Accepted: April 11, $2017 \quad$ Published: April 20, 2017

Copyright: Heng et al. This is an open-access article distributed under the terms of the Creative Commons Attribution License 3.0 (CC BY 3.0), which permits unrestricted use, distribution, and reproduction in any medium, provided the original author and source are credited.

\section{ABSTRACT}

Endometrial cancer is one of the most common gynecological malignancies affecting post-menopausal women, yet the underlying mechanisms are not well understood. Dystroglycan (DG) is a large glycoprotein, consisting of $\alpha$ - and $\beta$-subunits that are non-covalently associated with each other. Modifications to a-DG have been linked to a variety of cancers, where the $\mathbf{N}$-terminus of a-DG ( $\mathbf{a}-\mathrm{DG}-\mathbf{N}$ ) is posttranslationally removed by a furin-like enzyme. However, the functional significance of a-DG-N removal is unknown. Our previous studies have established that the a-DG cleavage enzyme furin is significantly up-regulated in endometrial cancer. This study aimed to investigate the importance of a-DG-N removal in post-menopausal endometrial cancer. We demonstrated that a-DG-N removal predominantly occurred in early stage endometrial cancer tissues, and that the cleaved a-DG-N was significantly elevated in the uterine lavage of early grade endometrial cancer patients. Furthermore, a-DG-N removal significantly decreased the tight junction integrity and polarity of the endometrial epithelial cells, promoting the loss of polarity markers scribble and atypical protein kinase $\mathrm{C}$ ( $\mathrm{aPKC}$ ) and reducing the trans-epithelial electrical resistance. The removal of a-DG-N also sensitized the cells for estrogen-dependent proliferation. These results strongly suggest that a-DG-N removal plays an important role in early stage development of endometrial cancer, and that the elevated levels of a-DG-N in uterine fluid may provide a biomarker for early detection of endometrial cancer.

\section{INTRODUCTION}

Endometrial cancer is one of the most common gynecological malignancies [1], predominantly affecting women in their post-menopausal years. However, recent studies show that up to $30 \%$ of women diagnosed with endometrial cancer are pre-menopausal and this incidence is increasing in line with the increasing prevalence of obesity [2].

According to the International Federation of Gynecology and Obstetrics, endometrial cancer is graded as follows: grade 1, tumor is well differentiated with $5 \%$ solid growth pattern; grade 2 , tumor is moderately differentiated with 5-50\% solid growth pattern; and grade 3 , tumor is poorly differentiated with $50 \%$ solid non-morular pattern [3-5]. Based on clinical, endocrine and epidemiological characteristics, endometrial cancers are also classified as either type I or type II [6, 7]. Type I endometrial tumors are estrogen dependent, associated with endometrial hyperplasia and have favorable outcomes [6-8]. Type P tumors are estrogen independent, associated with endometrial atrophy and have less favorable outcomes [6-8].

Diagnosing endometrial cancer at early and confined stages is often problematic for cycling women where no obvious symptoms are detected, whilst symptoms 
such as vaginal bleeding in post-menopausal women are an indicator that the cancer has already progressed. The most common effective treatment following such diagnosis is abdominal hysterectomy (total removal of the uterus). Identifying novel molecules and pathways associated with early stage endometrial cancer is important for early diagnosis and non-surgical management. Minimally invasive tests that can be performed at routine gynecological checkup are currently non-existent.

Early changes in cellular function for cancer development include the loss of tight junction integrity, apical-basal polarity and cell-to-cell contacts. These are strong indicators that the cells are losing polarity and entering into an epithelial-mesenchymal transition (EMT), a key phenotype of early cancer progression [9-12]. The hallmark of EMT involves cellular loss of epithelial-specific adherens and tight junction proteins such as E-cadherin and occludin in association with loss of cell-cell contact and cell polarity $[13,14]$. Furthermore, disruption in apical-basal epithelial polarity affects three major protein complexes, the PAR complex, located on the apical junction domain of the epithelial cell, is and important for the formation of the tight junction $[15,16]$; the crumbs complex, localized to the apical membrane for interacting with the PAR complex [17, 18]; and the scribble complex, localized in the basolateral domain of the epithelial cells $[19,20]$.

Dystroglycan (DG), a large cell surface glycoprotein, has been linked to a number of cancers [21-26]. However, its role in human endometrial cancer remains largely unknown. DG is ubiquitously expressed in epithelial cells, and plays an important role in cell adhesion as a linker between the extracellular matrix and the cytoskeleton. DG, encoded by the DAG1 gene [27], is initially synthesized as one precursor protein, which is then posttranslationally cleaved into two non-covalently associated $\alpha$ - and $\beta$-subunits [28]. The $\beta$-DG subunit is anchored within the plasma membrane, whereas $\alpha-D G$ is noncovalently associated with the extracellular N-terminus of $\beta$-DG. The $\alpha$-DG subunit contains a central mucin-like region [29, 30], which is heavily glycosylated [31, 32] and mediates cell adhesion. However, the central region of $\alpha-\mathrm{DG}$ is obstructed by its large N-terminus ( $\alpha-\mathrm{DG}-\mathrm{N}$, amino acid 30-312). Proteolytic cleavage at amino acid 312 removes $\alpha$-DG-N [30, 33, 34], exposing the central region of $\alpha$-DG to interact with extracellular proteins such as laminin and fibronectin $[30,35]$. The function of $\alpha-D G$ is also dependent on glycosylation [36]. Mutations in glycosyltranferase genes that impact on $\alpha-\mathrm{DG}$ glycosylation lead to hypo-glycosylation of $\alpha-\mathrm{DG}$, reducing its laminin binding activity [37]. DG also plays important roles in the formation of the basement membrane, as loss of DG has been linked to various epithelial cancers' progression [21-25, 38]. Loss of $\alpha$-DG expression correlates with high grades of malignancies and reduced survival rate in breast and prostate $[21,22]$, retina $[23,26]$, colon and gastric [24], cervix and vulvar cancer patients [25]. Loss of $\alpha-D G$ in cancer cell lines leads to loss of extracellular binding; this can result from alterations in $\alpha$-DG glycosylation or proteolytic cleavage of $\alpha-\mathrm{DG}$ by furin [39].

Furin is a member of the proprotein convertase (PC) family of serine proteases. It post-translationally cleaves precursor proteins at the motif of $(\mathrm{K} / \mathrm{R}-(\mathrm{X}) \mathrm{n}-, \mathrm{X}$ is any other amino acid) [40]. Furin is ubiquitously expressed and has a number of important functional roles in cancer [41]. We have previously demonstrated that furin is the only PC member that is significantly up-regulated in postmenopausal endometrial cancer tissues [4]. Consistent with this, total PC activity is also significantly increased in uterine lavage of endometrial cancer patients compared to control post-menopausal women [4]. Previous studies have reported that furin plays a direct role in the cleavage and removal of $\alpha-\mathrm{DG}-\mathrm{N}$ in breast cancer cells, and that this is inhibited by a PC inhibitor [39]. Furthermore, cleavage of $\alpha-\mathrm{DG}-\mathrm{N}$ at the predicted PC cleavage site (amino acid 312 ) has been confirmed with a purified GST- $\alpha-D G-N$ antibody [33].

To date, little is known about the significance of $\alpha-\mathrm{DG}-\mathrm{N}$ removal in cancer development. These present study investigated the importance of $\alpha-\mathrm{DG}-\mathrm{N}$ removal in influencing endometrial epithelial cell characteristics relevant to cancer development.

\section{RESULTS}

\section{Immunolocalization of $\alpha$-DG in human endometrial cancer tissues}

To assess the physiological relevance of $\alpha-\mathrm{DG}-\mathrm{N}$ removal in endometrial cancer, we immunostained the $\mathrm{C}$ - and N-termini of $\alpha$-DG ( $\alpha$-DG-C and $\alpha$-DG-N respectively) (Figure 1A) in tissues from post-menopausal women without (controls) and with different grades of endometrial cancer (grade 1, 2 and 3, $n=4-8$ per group). The $\alpha$-DG-C was immunolocalized to glandular epithelial cells in all endometrial cancer and control tissues that were examined (Figure $1 \mathrm{~B}-1 \mathrm{C}, 1 \mathrm{~F}-1 \mathrm{G}, 1 \mathrm{~J}-1 \mathrm{~K}$ and $1 \mathrm{~N}-1 \mathrm{O})$. Similar localization was observed for $\alpha-\mathrm{DG}-\mathrm{N}$ (Figure 1D-1E, 1H-1I, 1L-1M, 1P-1Q). Compared to controls (Figure 1B-1C, 1R), the staining intensity of $\alpha$-DG-C was significantly elevated in grade 1 cancer (Figure $1 \mathrm{~F}-1 \mathrm{G}, 1 \mathrm{R}$ ), showed no difference in grade 2 (Figure 1J-1K, 1R), but was significantly reduced in grade 3 cancer (Figure $1 \mathrm{~N}-1 \mathrm{O}, 1 \mathrm{R}$ ). These data demonstrate that $\alpha$-DG-C immunostaining intensity decreases with increasing grade of cancer. In contrast, the staining intensity of $\alpha$-DG-N was significantly reduced in grade 1 cancer (Figure 1H-1I, 1S), but not significantly altered in grade 2 or 3 cancer (Figure $1 \mathrm{~L}-1 \mathrm{M}$ and $1 \mathrm{P}-1 \mathrm{Q}$ respectively, and $1 \mathrm{~S})$ compared to controls (Figure 1D-1E, 1S).

If $\alpha-\mathrm{DG}-\mathrm{N}$ is removed, a reduction in the ratio of $\alpha$-DG-N over $\alpha$-DG-C would be expected. The $\alpha-D G-N / \alpha-$ DG-C ratio was less than one in grade 1 cancer but close 
to one in controls or grades 2 or 3 cancer (Figure 1T), consistent with $\alpha$-DG-N being post-translationally removed from the epithelial cells in grade 1 endometrial cancer. These results suggest that post-translational removal of $\alpha$-DG-N from the epithelial cells may be associated with early stage endometrial cancer development.

\section{Detection of $\alpha-D G-N$ in uterine fluid from endometrial cancer patients}

We next assessed whether the $\alpha-D G-N$ cleaved from endometrial tissue is detectable in uterine lavage and whether these levels are altered in endometrial cancer patients. ELISA assessment of uterine lavage demonstrated the presence of $\alpha$-DG-N in all samples examined (Figure 2).
The concentration of $\alpha-\mathrm{DG}-\mathrm{N}$ in the lavage was significantly higher in women with grade 1 cancer than controls (Figure 2). This difference was not observed in $>$ grade 1 endometrial cancer (Figure 2). This result is consistent with more $\alpha$-DG-N being cleaved from the endometrial surface in grade 1 cancer and accumulating within the uterine fluid, confirming the immunostaining data presented in Figure 1.

\section{Removal of $\alpha$-DG-N promotes the loss of polarity in endometrial epithelial cells}

To investigate the importance of $\alpha$-DG-N removal in early stage endometrial cancer development, we utilized our previously established Ishikawa cell lines stably

\section{A}
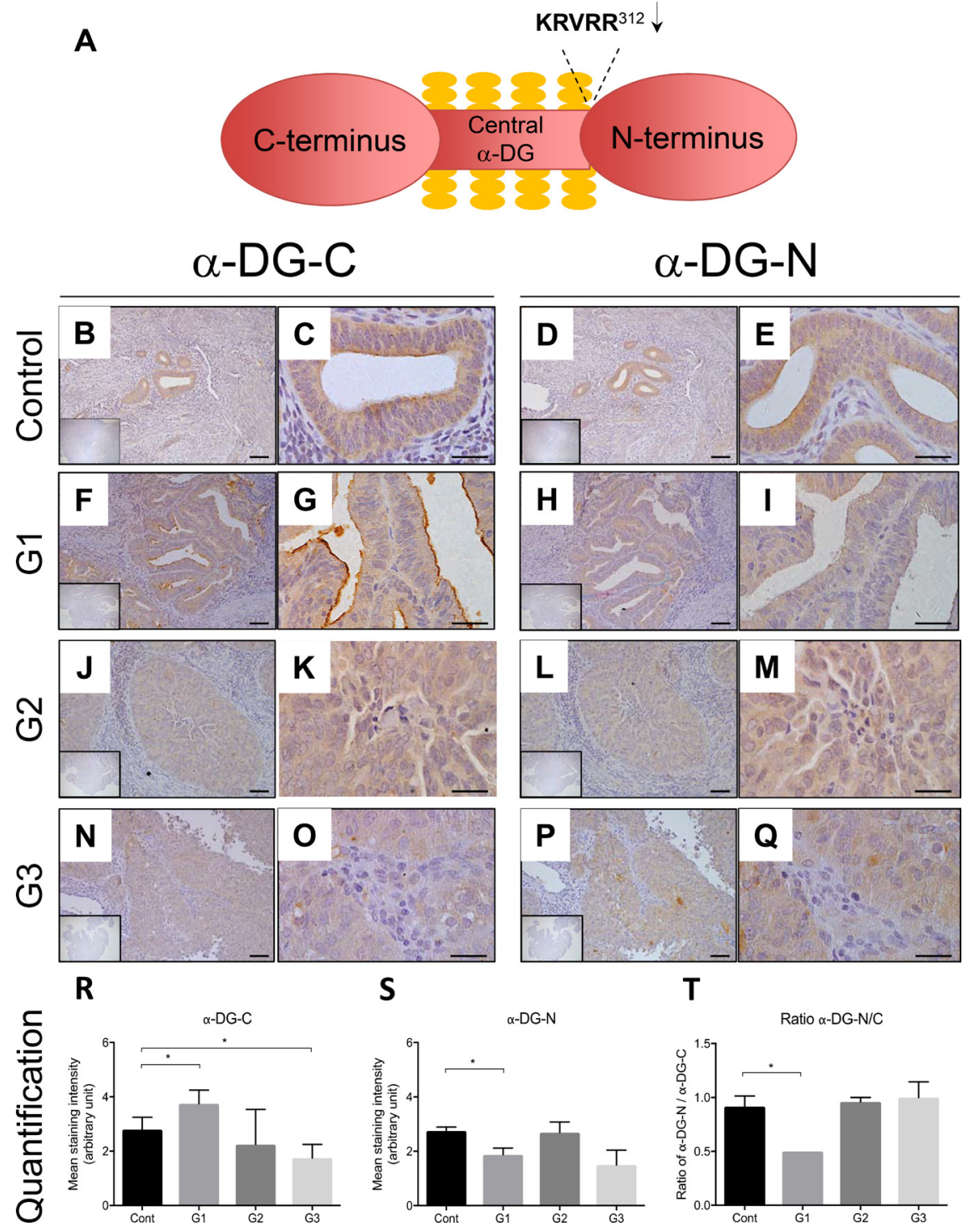

Figure 1: Representative images of immunolocalization of $\alpha$-DG in the endometrium of post-menopausal women without (control) and with endometrial cancer. Schematic diagram of $\alpha$-DG protein structure (Figure 1A). Serial sections were stained for $\alpha$-DG-C and $\alpha$-DG-N respectively for control $(\mathbf{B}-\mathbf{E})$, grade $1(\mathbf{F}-\mathbf{I})$, grade $2(\mathbf{J}-\mathbf{M})$, and grade 3 cancer sections $(\mathbf{N}-\mathbf{Q})$. The inserts are negative controls. (R) and (S) Mean intensity of glandular epithelial staining for $\alpha$-DG-C and $\alpha$-DG-N respectively. (T) The ratio of $\alpha-D G-N / \alpha-D G-C$. Each bar represents mean \pm SD $\left(n=4-8\right.$ for each phase), ${ }^{*} p<0.05$. 
expressing wild-type-DG (WT-DG, which contains the furin-cleavage site) and mutant-DG (Mut-DG, in which the PC-cleavage site was mutated to prevent $\alpha$-DG-N cleavage) [30]. The only difference between WT-DG and Mut-DG is a single amino acid mutation at the PC cleavage site at amino acid 312 (Figure 3A). Western blot of cell lysates detected elevated levels of $\beta$-DG in both WT-DG and Mut-DG cells compared to control Ishikawa cells (Figure 3B), confirming overexpression of DG in both WT-DG and Mut-DG cells. No $\beta$-DG was detected in the media as expected (Figure $3 \mathrm{~B}$ ), since $\beta-\mathrm{DG}$ is a membrane subunit of the DG complex. However, $\alpha-D G-N$ showed a different pattern between WT-DG and MutDG cells. A strong dominant band of approximately 37 $\mathrm{kDa}$, consistent with the size of the cleaved $\alpha-\mathrm{DG}-\mathrm{N}$, was detected in both the lysates and media of WT-DG cells (Figure 3B). In contrast, Mut-DG cell media showed no band, but the lysates displayed an extra band of approximately $150 \mathrm{kDa}$ that is consistent with the intact $\alpha$-DG (Figure 3B). These data validated that in Mut-DG cells the cleavage and release of $\alpha-\mathrm{DG}-\mathrm{N}$ was prevented.

As loss of epithelial cell apical-basal polarity is a hallmark of early stage cancer development, we next determined whether cleavage of $\alpha$-DG-N was important for cell polarity and monolayer integrity. Trans-epithelial electrical resistance (TER) was measured as a proxy readout of polarity in the DG-manipulated Ishikawa cells. Each cell line was grown to a confluent monolayer on transwell inserts, and TER readings were then taken every $24 \mathrm{hr}$ for $48 \mathrm{hr}$. All three cell lines showed a very similar TER at the start of the experiment (Figure 4A-4B). Over $48 \mathrm{hr}$ of culture, TER progressively increased in the control cells, consistent with the establishment of a continuous intact monolayer with apical-basal polarity. Cells expressing the mutated DG (Mut-DG) likewise increased TER progressively over time (Figure 4A-4B).
In contrast, in WT-DG cells, which release $\alpha$-DG-N, TER decreased over time (Figure 4A-1B), indicating that overexpression of WT-DG with the associated cleavage of $\alpha$-DG-N promoted the progressive loss of apical-basal polarity. These results suggested that $\alpha-D G-N$ removal influences $\alpha$-DG function and the loss of cellular apicalbasal polarity.

We further examined the apical-basal polarity markers scribble and atypical Protein Kinase C (aPKC) by immunofluorescence in these cell lines (Figure 4C). Membrane localization of scribble was seen in all cell lines. However, the staining intensity was greatly reduced in WT-DG cells versus controls (Figure 4C), while MutDG cells were not different from controls (Figure 4C). Immunostaining for aPKC showed a similar pattern to scribble (Figure 4C), again the staining was reduced in WT-DG but not in Mut-DG cells or controls. Because of this observation, we immunostained aPKC in the tissues investigated in Figure 1. The staining intensity of aPKC was significantly lower in grade 1 cancer tissues compared to the controls (Supplementary Figure 1). These results further confirmed that $\alpha$-DG-N cleavage affected the presentation of polarity markers scribble and aPKC, consistent with $\alpha$-DG-N removal regulating the apicalbasal epithelial polarity to promote depolarization, which is a key phenotype in early cancer progression.

\section{Cleavage of $\alpha$-DG-N promotes estrogen-dependent cell proliferation}

As elevated levels of estrogen in post-menopausal women are a major risk factor for endometrial cancer development [42], we next assessed whether cleavage of $\alpha$-DG-N affects estrogen-dependent cell proliferation. When treated with vehicle control (ethanol only), cell proliferation was similar between control and WT-DG

\section{Lavage}

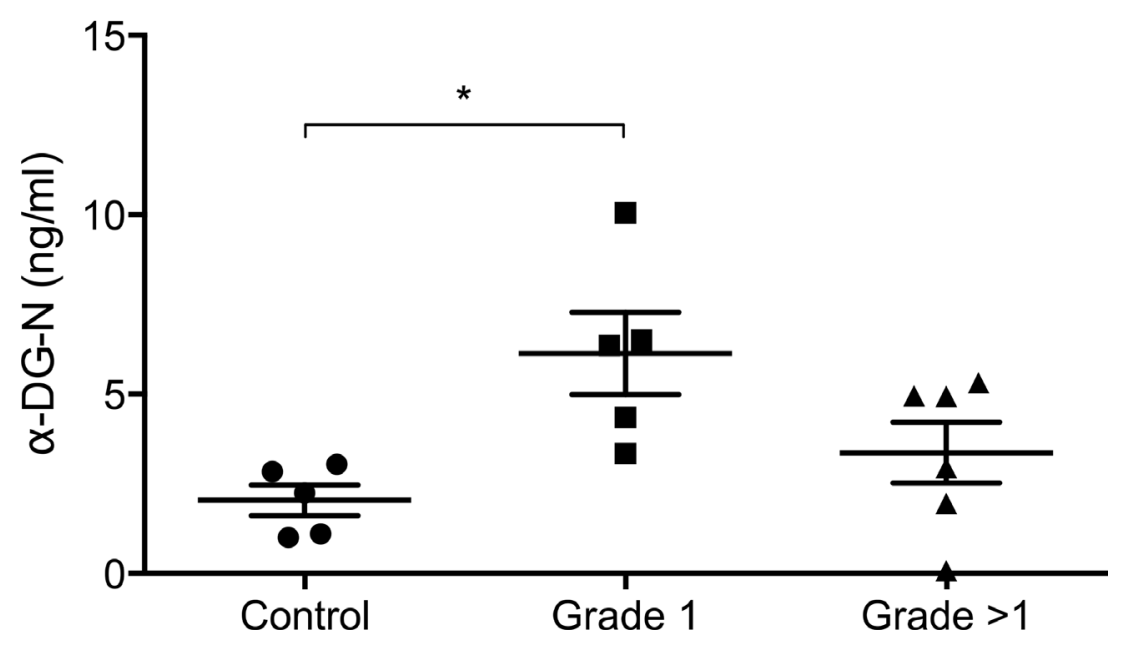

Figure 2: ELISA detection of $\boldsymbol{\alpha}-\mathrm{DG}-\mathbf{N}$ in the uterine lavage. Significantly higher concentrations of $\alpha$-DG-N were detected in grade 1 endometrial cancer compared to control post-menopausal women, ${ }^{*} p<0.05$. 
but reduced in Mut-DG, so that the proliferation rate of WT-DG cells was significantly greater than Mut-DG cells at $24 \mathrm{hr}$, but not $48 \mathrm{hr}$ (Figure 5A). In the presence of $10 \mathrm{nM}$ estrogen, compared to control cells, the WT-DG cells proliferated significantly faster, whereas the Mut-DG cells proliferated significantly slower (Figure 5B). These differences were obvious at $24 \mathrm{hr}$ and became significant at $48 \mathrm{hr}$ (Figure 5B). As the only difference between the WT-DG and Mut-DG is the presence or absence of $\alpha$-DG-N cleavage, these results provide evidence that
$\alpha$-DG-N removal from the cell surface promotes estrogendependent endometrial epithelial cell proliferation.

\section{DISCUSSION}

The mechanisms underlying endometrial cancer development, especially during the early stages of the disease are poorly understood. This study demonstrated that post-translational modification of DG may play an important role in early stage development of endometrial

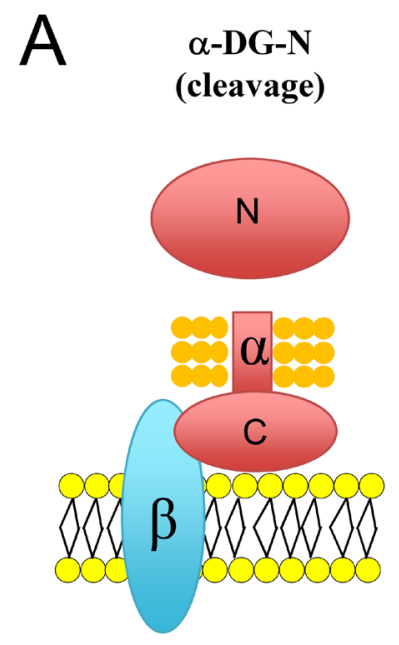

WT-DG

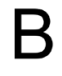

B
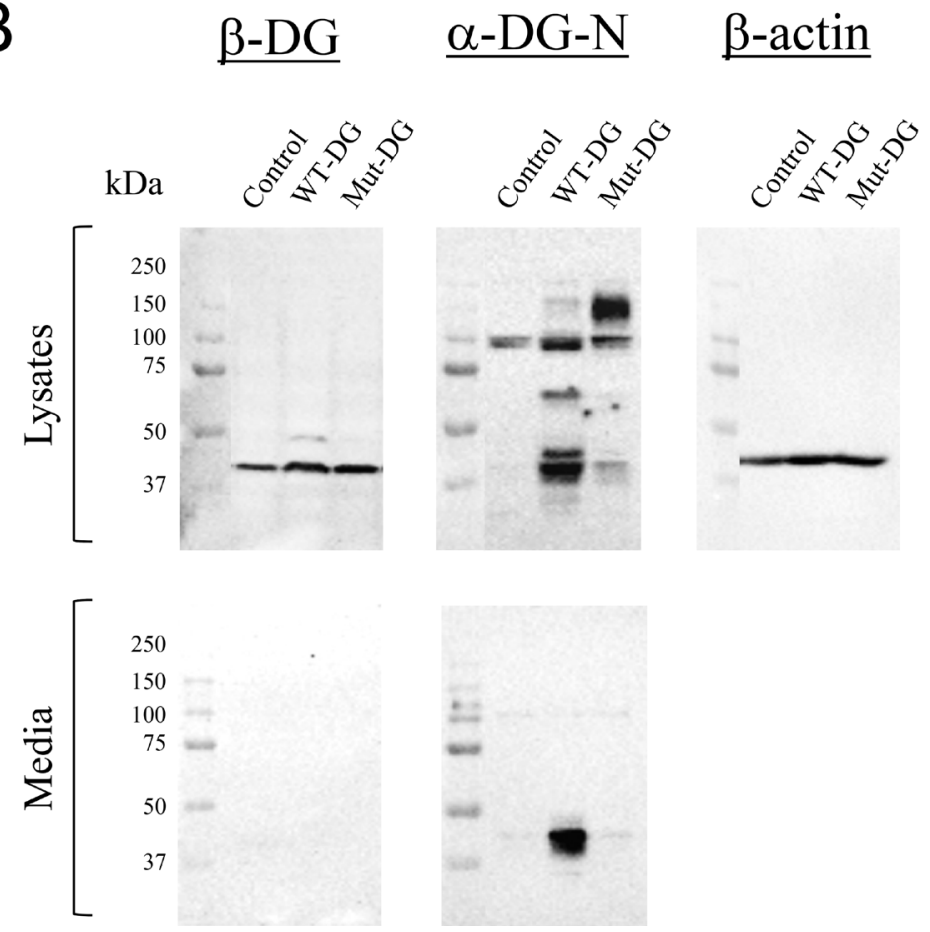

DG antibody epitope locations

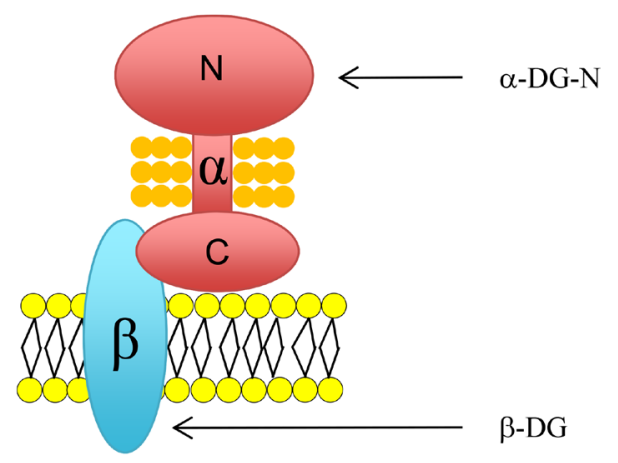

Mut-DG 
cancer. DG mediates cell adhesion through the central glycosylated region of $\alpha-\mathrm{DG}$. However, this region is obstructed by its large N-terminus ( $\alpha$-DG-N), which is known to be removed from the cell surface by a furin-like PC enzyme in cancer [39]. We previously reported that furin is the only $\mathrm{PC}$ that is up-regulated in endometrial cancer in post-menopausal women [4]. In this study, we proved by immunolocalization that
$\alpha-D G-N$ was removed from the endometrial epithelial cells of grade 1 cancer, and that $\alpha$-DG-N levels in uterine fluids were significantly elevated in grade 1 endometrial cancer patients.

The significance of $\alpha-\mathrm{DG}-\mathrm{N}$ removal in early stage endometrial epithelial cancer was further investigated by utilizing Ishikawa cells stably expressing different forms of $\alpha$-DG [30]. WT-DG cells express $\alpha$-DG that contains the
A

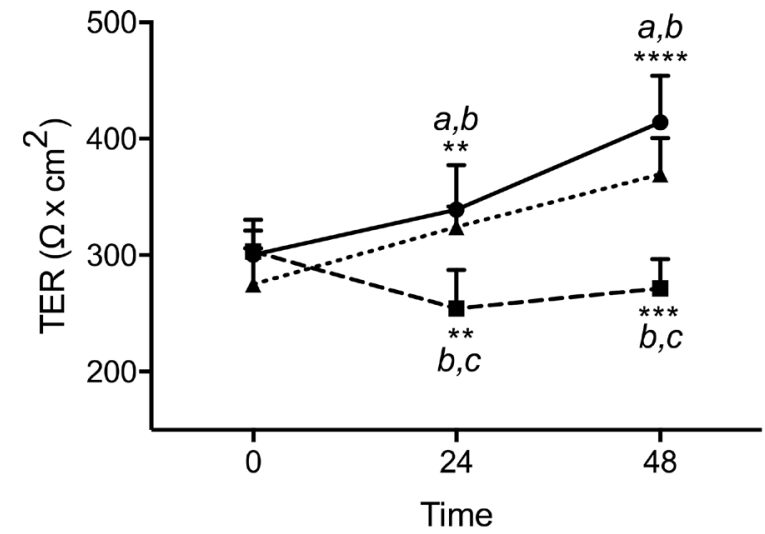

B
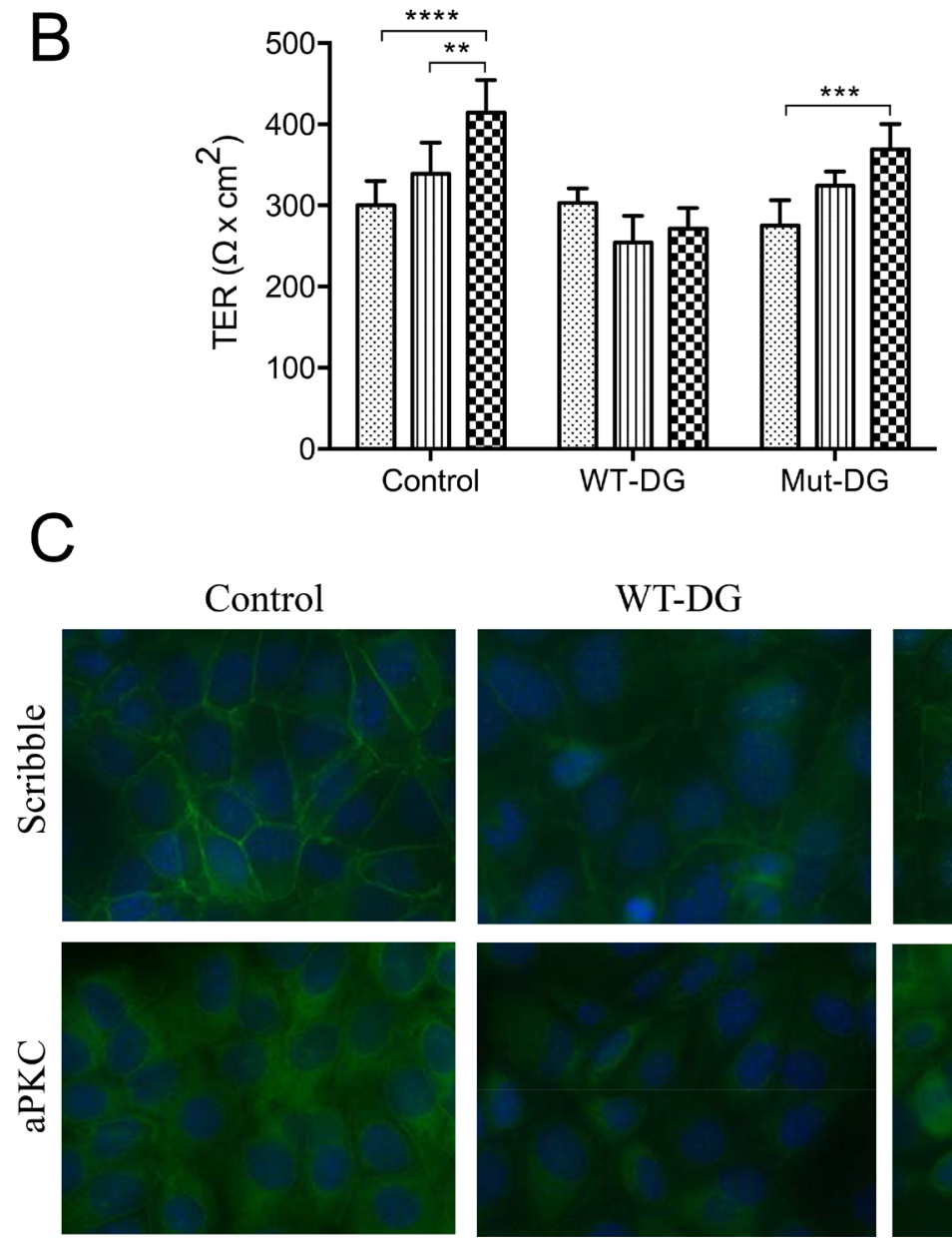

a $\rightarrow$ Control

$b \rightarrow$ WT-DG

c.... Mut-DG

Ohr
띠 24hr
D. $48 \mathrm{hr}$
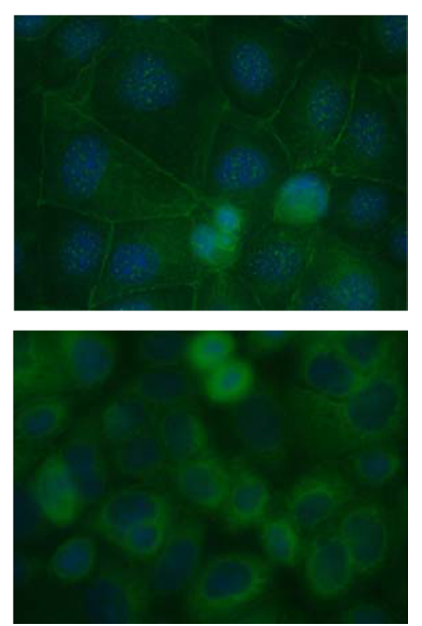

Figure 4: Trans-epithelial electrical resistance (TER) and tight junction integrity in different DG stable cell lines. (A-B) TER of control, WT-DG and Mut-DG cells at 0,24 and $48 \mathrm{hr}$ of culture. Data presented are mean $\pm \operatorname{SD}(n=4)$, ** $p<0.005$, $* * * p<0.0005$ and $* * * * p<0.0001$. (C) Immunofluorescence staining for cell polarity marker proteins scribble and aPKC in green. Nuclei were stained for DAPI in blue. 
furin-cleavage site, and release $\alpha-\mathrm{DG}-\mathrm{N}$, while the MutDG cells express $\alpha$-DG that lacks the furin-cleavage site and hence $\alpha-\mathrm{DG}-\mathrm{N}$ is retained on the cell surface. Transepithelial electrical resistance measurement demonstrated that the removal of $\alpha-\mathrm{DG}-\mathrm{N}$ profoundly decreased tight junction integrity, in that WT-DG cells were significantly less polarized than the control (empty vector) or MutDG cells. Scribble, one of the key protein responsible for establishing apical-basal cell polarity binds to proteins such as E-cadherin to further stabilize cell adhesion [19]. Additionally, scribble is a potential tumor suppressor as its down-regulation is often associated with cancer $[43,44]$. The aPKC protein is part of the PAR complex, which is localized at the apical side of the tight junction and functions to promote the formation of tight junctions $[16,45]$. In this study, the removal of $\alpha-\mathrm{DG}-\mathrm{N}$ reduced the presentation of scribble and aPKC in WT-DG compared to control or Mut-DG cells, providing a mechanism underpinning the disruption of tight junction integrity and apical-basal polarity, promoting cell depolarization.

The loss of tight junction integrity is a strong indication that the cells are undergoing an epithelialmesenchymal transition (EMT), a key phenotype in early cancer progression [9, 11, 46, 47]. Destabilization of cellcell adherens junctions and tight junctions are important for cells to enter into EMT. The transition of polarized epithelial cells into a plastic and motile mesenchymal phenotype is initially due to the breakdown of tight junction integrity and disruption in three major protein complexes (PAR, crumbs and scribble) that are important for apical-basal cell polarity $[9,46]$. This is followed by the weakening and breakdown of adherens junctions and desmosomes [46] through post-translational modifications of proteins such as E-cadherin and $\beta$-catenin $[48,49]$ and transcriptional repression such as zinc finger E-boxbinding homeobox (ZEB) and Snail [50-53]. In this

\section{A Vehicle control}
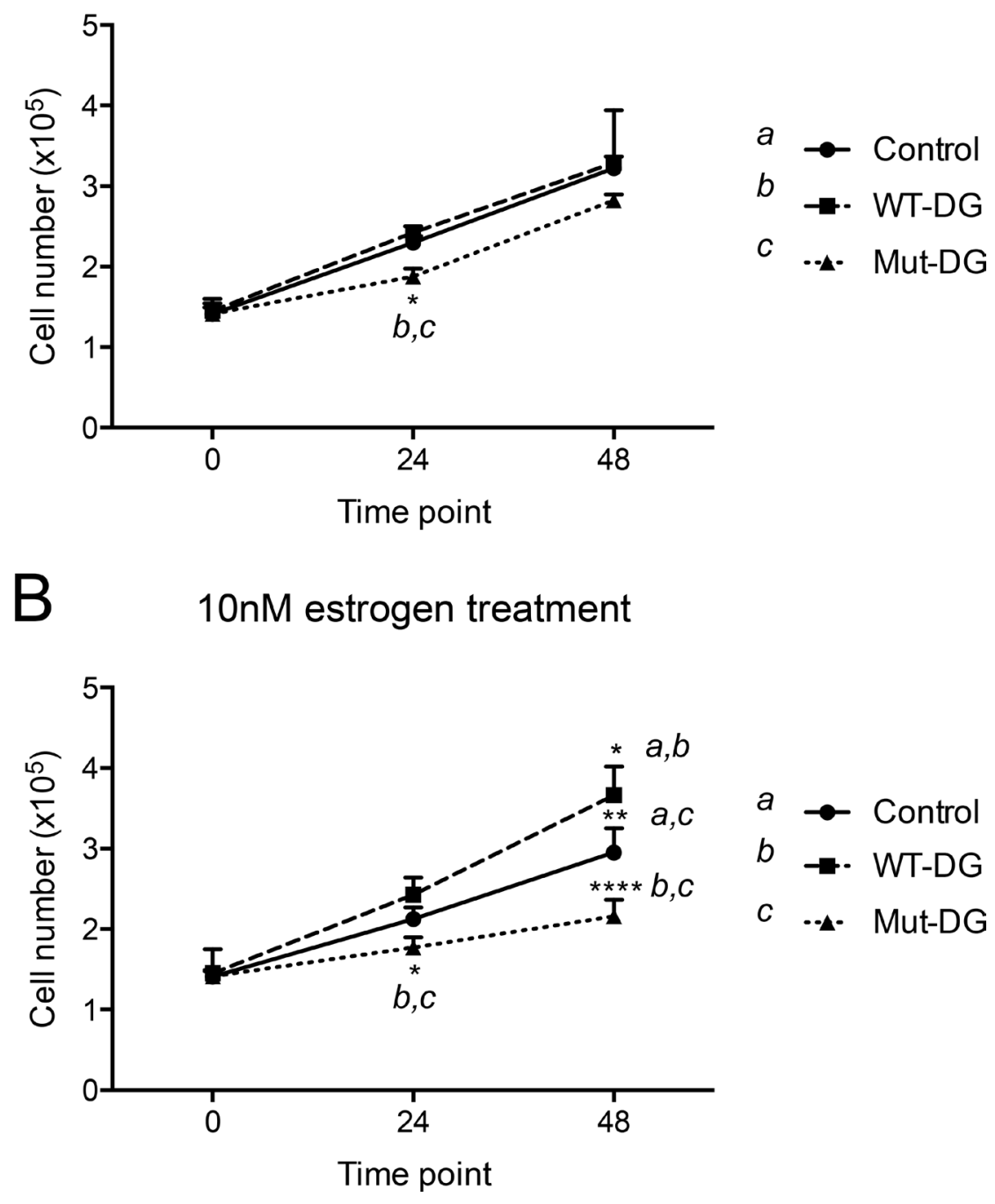

Figure 5: Proliferation of DG stable cells in the absence and presence of estrogen. (A) Cells in vehicle control for 0,24 and $48 \mathrm{hr}, * p<0.05$. (B) Cells in $10 \mathrm{nM}$ estrogen, $* p<0.05, * * p<0.005$ and $* * * * p<0.0001$. 
study, the removal of $\alpha$-DG-N from the cell surface led to disruption of scribble and the PAR complex protein aPKC. Further studies are required to investigate how $\alpha-D G-N$ removal influences these changes.

Elevated levels of estrogen are associated with endometrial cancer development in post-menopausal women [42], with the main source of estrogen production being adipose tissues. Elevated estrogen production from adipose tissues, in obesity and the use of hormone replacement therapy are linked to cancer development in such women $[54,55]$. In this study, $\alpha-\mathrm{DG}-\mathrm{N}$ removal significantly promoted estrogen-dependent proliferation of endometrial epithelial cells.

In summary, we have demonstrated that the removal of $\alpha$-DG-N plays an important role during early stage development of endometrial cancer. The removal of $\alpha$-DG-N decreases tight junction integrity and cell polarity, which are directly related to epithelial-mesenchymal transition. The removal of $\alpha$-DG-N also sensitizes the cells for estrogen-dependent cell proliferation. The molecular mechanisms governing these effects will need to be further investigated. Furthermore, $\alpha-\mathrm{DG}-\mathrm{N}$ cleaved from the endometrial epithelium is released into the uterine cavity. Thus elevated $\alpha$-DG-N in uterine fluid may provide a potential biomarker for non-invasive detection of early stage endometrial cancer in post-menopausal women.

\section{MATERIALS AND METHODS}

\section{Clinical material collection}

Ethical approval was obtained from the Human Ethics Committee at Monash Medical Centre (Melbourne, Australia) and written informed consent was provided by individual patient. Endometrial biopsies from postmenopausal control $(n=5)$ and endometrial cancer patients $(n=16)$ were fixed in formalin and embedded in wax as previously described [3]. Endometrial cancer grade (G) (G1, $n=4$; G2, $n=8$ and G3, $n=4)$ were confirmed by histological grading [3]. Uterine lavages $(n=16)$ were obtained from women with $(n=11)$ or without $(n=5)$ endometrial cancer. Tissues and lavages were collected from different patients for this study. In brief, $3 \mathrm{ml}$ of sterile saline was gently infused transcervically through a fine flexible catheter into the uterine cavity, and the uterine fluid was recovered by aspiration. Cell debris was removed by centrifugation for $5 \mathrm{~min}$ at $1000 \mathrm{rpm}$ and aliquots were stored at $-80^{\circ} \mathrm{C}$.

\section{Immunohistochemical localization of $\alpha-D G$ and aPKC in human endometrial tissues}

Sections of $\mu \mathrm{M}$ were de-paraffinized in histosol, rehydrated and microwaved for $10 \mathrm{~min}$ in $0.01 \mathrm{~mol} / \mathrm{L}$ citrate buffer ( $\mathrm{pH}$ 6.0) for antigen retrieval. Endogenous peroxidase was quenched with $3 \% \mathrm{H}_{2} \mathrm{O}_{2}$ in methanol for
10 min and non-specific binding was blocked with preimmune serum. The sections were incubated for $1 \mathrm{hr}$ at $37^{\circ} \mathrm{C}$ with primary antibodies for $\alpha-\mathrm{DG}-\mathrm{C}(\mathrm{C} 15$ at $5 \mu \mathrm{g} / \mathrm{ml}$, Santa Cruz Inc., California, USA) and aPKC (at $1 \mu \mathrm{g} / \mathrm{ml}$, Santa Cruz Inc., California, USA) or overnight at $4^{\circ} \mathrm{C}$ for $\alpha$-DG-N (WH00 at $6 \mu \mathrm{g} / \mathrm{ml}$, Sigma Aldrich, NSW, Australia). Mouse or goat IgG (Dako, NSW, AUS) replaced the primary antibodies as the respective negative controls. Sections were washed and appropriate biotinylated secondary antibodies (Vector laboratories, Inc. USA) were applied for $30 \mathrm{~min}$ at room temperature. Signals were amplified with StreptABC/HRP (Dako) for $30 \mathrm{~min}$ at room temperature and visualized with diaminobenzidine (Dako). The relative immunostaining intensity in epithelial cells within the entire tissue section was evaluated and scored semi-quantitatively by two independent observers $(0=$ no staining, 4 = maximal staining). The data was expressed as the mean intensity $\pm \mathrm{SD}$.

\section{ELISA detection of $\alpha$-DG-N in human uterine lavage of endometrial cancer patients}

A previously established ELISA for the detection of $\alpha$-DG-N in uterine lavage was used [56]. In brief, half area 96-well plates were coated overnight at $4^{\circ} \mathrm{C}$ with $0.5 \mu \mathrm{g} / \mathrm{ml}$ of $\alpha$-DG-N mAb (2A3, Sigma Aldrich) in 0.1 M sodium carbonate/bicarbonate buffer of pH 9.6 (Sigma Aldrich). The wells were then washed with PBS (137 mM NaCl, $2.7 \mathrm{mM} \mathrm{KCl}, 10 \mathrm{mM} \mathrm{Na}_{2} \mathrm{HPO}_{4}$ and $1.8 \mathrm{mM} \mathrm{KH}_{2} \mathrm{PO}_{4}$ ) containing $0.05 \%$ Tween20 (PBS-T), and blocked with $1 \%$ BSA (Bovogen, VIC, Australia) in PBS for $90 \mathrm{~min}$ at $37^{\circ} \mathrm{C}$. The wells were washed with PBS-T, incubated with recombinant $\alpha$-DG-N as the standards or uterine lavage (undiluted) for $2 \mathrm{hr}$ with gentle agitation. The wells were washed and incubated first with $3 \mu \mathrm{g} / \mathrm{ml}$ of biotinylated detection antibody (3B4, Creative Diagnostics, NY, USA) for $1 \mathrm{hr}$, then with poly streptavidin-HRP (Thermo Scientific, Waltham, MA, USA) at 1:25,000 dilution for 50 min with gentle agitation, and finally with ultra-TMB substrate (undiluted, Thermo Scientific) for 7-10 min in the dark at room temperature without agitation. The ELISA reaction was stopped with $1 \mathrm{M}$ sulfuric acid (Banksia Scientific Company Pty Ltd, QLD, AUS) and the absorbance at $450 \mathrm{~nm}$ was measured (Envision Multilabel reader, PerkinElmer, Waltham, MA, USA). All washes and incubations were performed at room temperature.

\section{Culture of Ishikawa cells stably expressing different forms of $\alpha$-DG}

Ishikawa cells (generous gift by Professor Masato Nishida of National Hospital Organization, Kasumigaura Medical Center, Ibaraki-ken, Japan), were validated by karyotype analysis via Short Tandem Repeat (STR) DNA profiling of human cell lines per ATCC guidelines [57]. Ishikawa cells were stably transfected with constructs to 
express control (empty vector), wild-type (WT) or mutant (Mut) DG that lacks the PC cleavage site [30]. These DG stable cells were cultured in complete media containing Modified Eagle's Medium (MEM, Life Technologies, Carlsbad, CA, USA) supplemented with 10\% (v/v) fetal calf serum (FCS) (Life Technologies) and 2\% geneticin (Sigma, USA) at $37^{\circ} \mathrm{C}$. For estrogen treatment, cells were grown in complete media containing MEM supplemented with $10 \%(\mathrm{v} / \mathrm{v})$ charcoal-stripped fetal calf serum (csFCS) (Life Technologies) and 2\% geneticin.

\section{Protein extraction and Western blot analysis}

DG stable cells were lysed with $50 \mathrm{mM}$ Tris/HCl (pH 7.4), $150 \mathrm{mM} \mathrm{NaCl}, 1 \%$ (v/v) Triton X-100, $1 \mathrm{mM}$ EGTA and $2 \mathrm{mM}$ EDTA containing protease inhibitors (Calbiochem, Darmstadt, Germany), and proteins were collected following centrifugation $(14,000 \mathrm{rpm}$ for $10 \mathrm{~min}$ at $4^{\circ} \mathrm{C}$ ). To collect serum-free conditioned media, cells were seeded at the same density grown to approximately $80 \%$ confluency in complete media, then washed with PBS and grown in serum-free MEM media containing 2\% geneticin for a further $48 \mathrm{hr}$. Protein concentrations were determined by a Bradford assay (Bio-rad Laboratories CA, USA), and standard western blot (10\% SDS-PAGE gel) was performed using primary antibodies for $\beta$-DG (4F7 at $1 \mu \mathrm{g} / \mathrm{ml}$, Santa Cruz) and $\alpha-\mathrm{DG}-\mathrm{N}$ (WH00 at $1 \mu \mathrm{g} / \mathrm{ml}$, Sigma Aldrich) with appropriate anti-HRP secondary antibodies (Dako, NSW, AUS). To confirm equal loading, blots were stripped and re-probed for $\beta$-actin using a HRP-conjugated antibody $(0.4 \mu \mathrm{g} / \mathrm{ml}$, Cell Signaling, MA, USA).

\section{Trans-epithelial Electrical Resistance (TER) measurement}

Permeable transwell inserts $(6.5 \mathrm{~mm}, 0.4 \mu \mathrm{m}$ pore, Corning, NY, USA) were coated with $10 \mu \mathrm{g} / \mathrm{ml}$ fibronectin (BD Bioscience, NSW, AUS) for $1 \mathrm{hr}$ at room temperature. DG stable cell lines were seeded $\left(4 \times 10^{4}\right.$ cells per insert) on fibronectin-coated inserts and allowed to attach overnight in complete media. They were then incubated in serum-free media containing $2 \%$ geneticin in the upper chambers and complete media in the lower chambers. Trans-epithelial electrical resistance (TER) was measured daily using a Millipore MilliCell-Electrical Resistance System (Millipore, Massachusetts, United States), commencing from the day of media change (Day 1 or otherwise $0 \mathrm{hr}$ ). Cells were maintained at $37^{\circ} \mathrm{C}$ throughout the experiment. Following the removal of the plate from the incubator and before TER measurement, cells were equilibrated on a warming plate within the culture hood for approximately $10 \mathrm{~min}$. Four TER readings (ohm per $\mathrm{cm}^{2}$ ) were taken from each well and readings from duplicate wells per cell line were averaged to obtain the raw TER; the final value was obtained after subtraction of background TER which was obtained from inserts that contained no cells in the same experiment. The entire experiments were repeated independently four times and the data was expressed as mean $\pm \operatorname{SD}(n=4)$.

\section{Immunofluorescence analysis}

DG stable cells were grown on chamber slides, fixed in $100 \%$ methanol, and blocked with $10 \%$ goat serum, $2 \%$ human serum, $0.1 \%$ fish skin gelatin and $0.1 \%$ Triton X-100 in PBS containing $0.2 \%$ Tween 20 for $1 \mathrm{hr}$ at room temperature. Cells were probed first with primary antibodies for scribble (at $5 \mu \mathrm{g} / \mathrm{ml}$, Abcam, MA, USA) or aPKC (at $2 \mu \mathrm{g} / \mathrm{ml}$, Santa Cruz, California, USA) overnight at $4{ }^{\circ} \mathrm{C}$, then with a goat anti-rabbit biotinylated secondary antibody (Vector Laboratories, Inc. USA) for $1 \mathrm{hr}$ at room temperature, and Alexa 488 (at $5 \mu \mathrm{g} / \mathrm{ml}$, Invitrogen, Molecular Probes, Carlsbad, CA) for $2 \mathrm{hr}$ at room temperature. The nuclei were stained with DAPI (at $0.5 \mathrm{mg} / \mathrm{ml}$, Sigma Aldrich) and the signal was visualized by fluorescence microscopy (Olympus BX53).

\section{Cell proliferation and estrogen treatment}

DG cell lines were first cultured in 12-well plates $\left(1 \times 10^{5}\right.$ cells per well) for $24 \mathrm{hr}$ in complete media containing $10 \% \mathrm{csFCS}$, then changed to fresh complete media containing vehicle control (VC, ethanol only) or $10 \mathrm{nM}$ estrogen (E) (17 $\beta$-estradiol, Sigma, USA, diluted in ethanol), and cultured for $24 \mathrm{hr}$ or $48 \mathrm{hr}$. Cells were trypsinized and counted using the Countess (Invitrogen, Carlsbad, CA, USA) to determine cell numbers before and after ( 24 and $48 \mathrm{hr}$ ) the treatment. The entire experiment was repeated independently 4 times $(n=4)$.

\section{Statistics}

Data were expressed as mean \pm SD. Statistical analysis was performed on raw data; comparisons between two groups used unpaired, non-parametric, Mann-Whitney test, multiple group comparisons used one-way ANOVA, non-parametric and Kruskal Wallis test (PRISM version 6.00, GraphPad Software, San Diego, CA). $* p<0.05$ was taken as significant; ** $p<0.005, * * * p<0.0005$ and $* * * * p<0.0001$ were considered highly significant.

\section{ACKNOWLEDGMENTS AND FUNDING}

This work was supported by the National Health and Medical Research Council of Australia [Project grant \#1108365 and Fellowship \#1041835 to G.N.), The CASS Foundation, an Australian Postgraduate Awards Scholarship and Cancer Council Victoria (to SH) and the Victorian Government Operational Infrastructure Support Program. We thank Professor Masato Nishida of National Hospital Organization, Kasumigaura Medical Center, 
Ibaraki-ken, Japan for providing the Ishikawa cells. We are grateful to our colleagues Dr Andrew N Stephens and research nurse Nicole Fairweather for collecting uterine fluids, and the patients who kindly donated uterine tissues and lavage samples for this study.

\section{CONFLICTS OF INTEREST}

The authors declare no potential conflicts of interest.

\section{REFERENCES}

1. Siegel RL, Miller KD, Jemal A. Cancer statistics, 2015. CA Cancer J Clin. 2015; 65:5-29.

2. Soliman PT, Oh JC, Schmeler KM, Sun CC, Slomovitz BM, Gershenson DM, Burke TW, Lu KH. Risk factors for young premenopausal women with endometrial cancer. Obstet Gynecol. 2005; 105:575-580.

3. Di Nezza LA, Misajon A, Zhang J, Jobling T, Quinn MA, Ostor AG, Nie G, Lopata A, Salamonsen LA. Presence of active gelatinases in endometrial carcinoma and correlation of matrix metalloproteinase expression with increasing tumor grade and invasion. Cancer. 2002; 94:1466-1475.

4. Singh H, Heng S, Nicholls PK, Li Y, Tai LT, Jobling T, Salamonsen LA, Nie G. Proprotein convertases in postmenopausal endometrial cancer: distinctive regulation and non-invasive diagnosis. Biochemical and biophysical research communications. 2012; 419:809-814.

5. Mikuta JJ. International Federation of Gynecology and Obstetrics staging of endometrial cancer 1988. Cancer. 1993; 71:1460-1463.

6. Bokhman JV. Two pathogenetic types of endometrial carcinoma. Gynecologic oncology. 1983; 15:10-17.

7. Felix AS, Weissfeld JL, Stone RA, Bowser R, Chivukula M, Edwards RP, Linkov F. Factors associated with Type I and Type II endometrial cancer. Cancer Causes Control. 2010; 21:1851-1856.

8. Setiawan VW, Yang HP, Pike MC, McCann SE, Yu H, Xiang YB, Wolk A, Wentzensen N, Weiss NS, Webb PM, van den Brandt PA, van de Vijver K, Thompson PJ, et al, and Australian National Endometrial Cancer Study Group. Type I and II endometrial cancers: have they different risk factors? J Clin Oncol. 2013; 31:2607-2618.

9. Gandalovicova A, Vomastek T, Rosel D, Brabek J. Cell polarity signaling in the plasticity of cancer cell invasiveness. Oncotarget. 2016; 7:25022-49. doi: 10.18632/ oncotarget. 7214 .

10. Guarino M, Rubino B, Ballabio G. The role of epithelialmesenchymal transition in cancer pathology. Pathology. 2007; 39:305-318.

11. Kalluri R, Weinberg RA. The basics of epithelialmesenchymal transition. J Clin Invest. 2009; 119:1420-1428.

12. Thiery JP. Epithelial-mesenchymal transitions in development and pathologies. Current opinion in cell biology. 2003; 15:740-746.

13. Abouhashem NS, Ibrahim DA, Mohamed AM. Prognostic implications of epithelial to mesenchymal transition related proteins (E-cadherin, Snail) and hypoxia inducible factor 1alpha in endometrioid endometrial carcinoma. Ann Diagn Pathol. 2016; 22:1-11.
14. Tobioka H, Isomura H, Kokai Y, Tokunaga Y, Yamaguchi J, Sawada N. Occludin expression decreases with the progression of human endometrial carcinoma. Human pathology. 2004; 35:159-164.

15. Goldstein B, Macara IG. The PAR proteins: fundamental players in animal cell polarization. Developmental cell. 2007; 13:609-622.

16. Horikoshi Y, Suzuki A, Yamanaka T, Sasaki K, Mizuno K, Sawada H, Yonemura S, Ohno S. Interaction between PAR-3 and the aPKC-PAR-6 complex is indispensable for apical domain development of epithelial cells. Journal of cell science. 2009; 122:1595-1606.

17. Assemat E, Bazellieres E, Pallesi-Pocachard E, Le Bivic A, Massey-Harroche D. Polarity complex proteins. Biochimica et biophysica acta. 2008; 1778:614-630.

18. Ngok SP, Lin WH, Anastasiadis PZ. Establishment of epithelial polarity--GEF who's minding the GAP? Journal of cell science. 2014; 127:3205-3215.

19. Qin Y, Capaldo C, Gumbiner BM, Macara IG. The mammalian Scribble polarity protein regulates epithelial cell adhesion and migration through E-cadherin. The Journal of cell biology. 2005; 171:1061-1071.

20. Vasioukhin V. Lethal giant puzzle of Lgl. Dev Neurosci. 2006; 28:13-24.

21. Henry MD, Cohen MB, Campbell KP. Reduced expression of dystroglycan in breast and prostate cancer. Human pathology. 2001; 32:791-795.

22. Muschler J, Levy D, Boudreau R, Henry M, Campbell $\mathrm{K}$, Bissell MJ. A role for dystroglycan in epithelial polarization: loss of function in breast tumor cells. Cancer research. 2002; 62:7102-7109.

23. Sgambato A, Camerini A, Amoroso D, Genovese G, De Luca F, Cecchi M, Migaldi M, Rettino A, Valsuani C, Tartarelli G, Donati S, Siclari O, Rossi G, Cittadini A. Expression of dystroglycan correlates with tumor grade and predicts survival in renal cell carcinoma. Cancer biology \& therapy. 2007; 6:1840-1846.

24. Sgambato A, Migaldi M, Montanari M, Camerini A, Brancaccio A, Rossi G, Cangiano R, Losasso C, Capelli G, Trentini GP, Cittadini A. Dystroglycan expression is frequently reduced in human breast and colon cancers and is associated with tumor progression. The American journal of pathology. 2003; 162:849-860.

25. Sgambato A, Tarquini E, Resci F, De Paola B, Faraglia B, Camerini A, Rettino A, Migaldi M, Cittadini A, Zannoni GF. Aberrant expression of alpha-dystroglycan in cervical and vulvar cancer. Gynecologic oncology. 2006; 103:397-404.

26. Shen JG, Xu CY, Li X, Dong MJ, Jiang ZN, Wang J, Wang LB. Dystroglycan is associated with tumor progression and patient survival in gastric cancer. Pathology oncology research: POR. 2012; 18:79-84.

27. Ibraghimov-Beskrovnaya $\mathrm{O}$, Milatovich A, Ozcelik $\mathrm{T}$, Yang B, Koepnick K, Francke U, Campbell KP. Human dystroglycan: skeletal muscle cDNA, genomic structure, origin of tissue specific isoforms and chromosomal localization. Human molecular genetics. 1993; 2:1651-1657.

28. Holt KH, Crosbie RH, Venzke DP, Campbell KP. Biosynthesis of dystroglycan: processing of a precursor propeptide. FEBS letters. 2000; 468:79-83. 
29. Brancaccio A, Schulthess T, Gesemann M, Engel J. Electron microscopic evidence for a mucin-like region in chick muscle alpha-dystroglycan. FEBS letters. 1995; 368:139-142.

30. Heng S, Paule SG, Li Y, Rombauts LJ, Vollenhoven B, Salamonsen LA, Nie G. Posttranslational removal of alphadystroglycan $\mathrm{N}$ terminus by PC5/6 cleavage is important for uterine preparation for embryo implantation in women. FASEB J. 2015; 29:4011-4022.

31. Gomez Toledo A, Raducu M, Cruces J, Nilsson J, Halim A, Larson G, Ruetschi U, Grahn A. O-Mannose and O-Nacetyl galactosamine glycosylation of mammalian alphadystroglycan is conserved in a region-specific manner. Glycobiology. 2012; 22:1413-1423.

32. Nilsson J, Larson G, Grahn A. Characterization of sitespecific O-glycan structures within the mucin-like domain of alpha-dystroglycan from human skeletal muscle. Glycobiology. 2010; 20:1160-1169.

33. Saito F, Saito-Arai Y, Nakamura A, Shimizu T, Matsumura $\mathrm{K}$. Processing and secretion of the N-terminal domain of alpha-dystroglycan in cell culture media. FEBS letters. 2008; 582:439-444.

34. Hesse C, Johansson I, Mattsson N, Bremell D, Andreasson U, Halim A, Anckarsater R, Blennow K, Anckarsater H, Zetterberg H, Larson G, Hagberg L, Grahn A. The $\mathrm{N}$-terminal domain of alpha-dystroglycan, released as a 38 $\mathrm{kDa}$ protein, is increased in cerebrospinal fluid in patients with Lyme neuroborreliosis. Biochemical and biophysical research communications. 2011; 412:494-499.

35. Montanaro F, Lindenbaum M, Carbonetto S. alphaDystroglycan is a laminin receptor involved in extracellular matrix assembly on myotubes and muscle cell viability. The Journal of cell biology. 1999; 145:1325-1340.

36. Michele DE, Campbell KP. Dystrophin-glycoprotein complex: post-translational processing and dystroglycan function. The Journal of biological chemistry. 2003; 278:15457-15460.

37. Michele DE, Barresi R, Kanagawa M, Saito F, Cohn RD, Satz JS, Dollar J, Nishino I, Kelley RI, Somer H, Straub V, Mathews KD, Moore SA, Campbell KP. Post- translational disruption of dystroglycan-ligand interactions in congenital muscular dystrophies. Nature. 2002; 418:417-422.

38. Sgambato A, Brancaccio A. The dystroglycan complex: from biology to cancer. Journal of cellular physiology. 2005; 205:163-169.

39. Singh J, Itahana Y, Knight-Krajewski S, Kanagawa M, Campbell KP, Bissell MJ, Muschler J. Proteolytic enzymes and altered glycosylation modulate dystroglycan function in carcinoma cells. Cancer research. 2004; 64:6152-6159.

40. Seidah NG, Mayer G, Zaid A, Rousselet E, Nassoury $\mathrm{N}$, Poirier S, Essalmani R, Prat A. The activation and physiological functions of the proprotein convertases. Int $\mathrm{J}$ Biochem Cell Biol. 2008; 40:1111-1125.

41. Bassi DE, Fu J, Lopez de Cicco R, Klein-Szanto AJ. Proprotein convertases: "master switches" in the regulation of tumor growth and progression. Mol Carcinog. 2005; 44:151-161.

42. Gambrell RD Jr. Prevention of endometrial cancer with progestogens. Maturitas. 1986; 8159-168.
43. Bilder D. Epithelial polarity and proliferation control: links from the Drosophila neoplastic tumor suppressors. Genes Dev. 2004; 18:1909-1925.

44. Sotelo NS, Valiente M, Gil A, Pulido R. A functional network of the tumor suppressors APC, hDlg, and PTEN, that relies on recognition of specific PDZ- domains. J Cell Biochem. 2012; 113:2661-2670.

45. Yamanaka T, Horikoshi Y, Suzuki A, Sugiyama Y, Kitamura K, Maniwa R, Nagai Y, Yamashita A, Hirose T, Ishikawa H, Ohno S. PAR-6 regulates aPKC activity in a novel way and mediates cell-cell contact-induced formation of the epithelial junctional complex. Genes Cells. 2001; 6:721-731.

46. Huang RY, Guilford P, Thiery JP. Early events in cell adhesion and polarity during epithelial-mesenchymal transition. Journal of cell science. 2012; 125:4417-4422.

47. Moreno-Bueno G, Portillo F, Cano A. Transcriptional regulation of cell polarity in EMT and cancer. Oncogene. 2008; 27:6958-6969.

48. D'Souza-Schorey C. Disassembling adherens junctions: breaking up is hard to do. Trends Cell Biol. 2005; 15:19-26.

49. Niessen CM. Tight junctions/adherens junctions: basic structure and function. J Invest Dermatol. 2007; 127:2525-2532.

50. Carrozzino F, Soulie P, Huber D, Mensi N, Orci L, Cano A, Feraille E, Montesano R. Inducible expression of Snail selectively increases paracellular ion permeability and differentially modulates tight junction proteins. Am J Physiol Cell Physiol. 2005; 289:C1002-1014.

51. De Craene B, Berx G. Regulatory networks defining EMT during cancer initiation and progression. Nat Rev Cancer. 2013; 13:97-110.

52. Peinado H, Olmeda D, Cano A. Snail, Zeb and bHLH factors in tumour progression: an alliance against the epithelial phenotype? Nat Rev Cancer. 2007; 7:415-428.

53. Vandewalle C, Comijn J, De Craene B, Vermassen P, Bruyneel E, Andersen H, Tulchinsky E, Van Roy F, Berx G. SIP1/ZEB2 induces EMT by repressing genes of different epithelial cell-cell junctions. Nucleic Acids Res. 2005; 33:6566-6578.

54. Akhmedkhanov A, Zeleniuch-Jacquotte A, Toniolo P. Role of exogenous and endogenous hormones in endometrial cancer: review of the evidence and research perspectives. Annals of the New York Academy of Sciences. 2001; 943:296-315.

55. Ricci E, Moroni S, Parazzini F, Surace M, Benzi G, Salerio B, Polverino G, La Vecchia C. Risk factors for endometrial hyperplasia: results from a case-control study. Int J Gynecol Cancer. 2002; 12:257-260.

56. Heng S, Vollenhoven B, Rombauts LJ, Nie G. A HighThroughput Assay for the Detection of alpha-Dystroglycan N-Terminus in Human Uterine Fluid to Determine Uterine Receptivity. J Biomol Screen. 2015.

57. Greening DW, Nguyen HP, Evans J, Simpson RJ, Salamonsen LA. Modulating the endometrial epithelial proteome and secretome in preparation for pregnancy: The role of ovarian steroid and pregnancy hormones. J Proteomics. 2016; 144:99-112. 